\title{
Effectiveness of Client-Centered Occupational Therapy in Patients With Rheumatoid Arthritis: Exploratory Randomized Controlled Trial
}

\author{
Eda TONGA, ${ }^{1}$ Tülin DÜGER, ${ }^{2}$ Metin KARATAŞ ${ }^{3}$ \\ ${ }^{1}$ Department of Physiotherapy and Rehabilitation, Başkent University, Faculty of Health Sciences, Ankara, Turkey \\ ${ }^{2}$ Department of Physiotherapy and Rehabilitation, Hacettepe University, Faculty of Health Sciences, Ankara, Turkey \\ ${ }^{3}$ Department of Physical Medicine and Rehabilitation, Medical Faculty of Başkent University, Ankara, Turkey
}

\begin{abstract}
Objectives: This study aims to examine the effectiveness of client-centered occupational therapy in patients with rheumatoid arthritis (RA). Patients and methods: The study included 40 patients ( 2 males, 38 females; range 39 to 60 years) with RA. Patients were divided into two groups as intervention group $(n=20)$ and control group $(n=20)$ by random sampling method. Each group was given 10 sessions of physical therapy program. In addition, the intervention group received client-centered occupational therapy. Patients were evaluated with Turkish versions of Short-Form McGill Pain Questionnaire, Health Assessment Questionnaire, The Arthritis Impact Measurement Scales 2, RA Quality of Life Questionnaire, and Canadian Occupational Performance Measurement.

Results: Pain, activity limitation, and participation restriction scores decreased significantly more in the intervention group compared to the control group. Also, quality of life increased significantly in the intervention group $(p<0.05)$.

Conclusion: Our findings suggest that occupational therapy intervention reduces activity limitation and participation restrictions in patients with RA. Therefore, such interventions may be generalized for this patient group.

Keywords: Client-centered approach; occupational therapy; rheumatoid arthritis.
\end{abstract}

Client-centered occupational therapy is a kind of partnership between the client/patient and the therapist, which allows empowerment of the patient to engage in functional performance to fulfill his/her occupational roles in a variety of environments. ${ }^{1}$ Philosophy of client-centered therapy includes empowerment and guiding of patients to achieve a cure by means of a balance of power between the therapist and patient. In this approach, the therapist acts as an educator. Thus, sufficient information and communication skills are needed to scrutinize the treatment. Expectations and targets are achieved together with the patient. ${ }^{2-4}$ When a client-centered approach can be administered completely, the patient makes decisions alone based on his/her targets. In addition, the power is transferred from the therapist to the patient. In such a case, the therapist supports the decision-making period of the patient and accepts his/her decisions. ${ }^{3,5}$

The Canadian Occupational Performance Measure (COPM) is a client-centered outcome measure that allows patients to evaluate their occupational performance and satisfaction with the performance in the areas of self-care, productivity, and leisure activities. ${ }^{6,7}$ However, majority of the studies have been designed to analyze the application of client-centered occupational therapy and/or COPM from 
therapists' perspectives, while few studies have focused on patients' views. Hammel ${ }^{3,8}$ asserted that the medical profession does not adopt clientcentered principles in all practices.

Rheumatoid arthritis (RA) is a chronic, disabling disease characterized by chronic inflammation of joints that, in most patients, results in progressive joint destruction with deformities and various degrees of limitation in daily activities. ${ }^{9}$ Disease severity can vary considerably even from day one to the next. The unpredictable and painful course of the disease cause a lot of stress on patients and greatly impact their quality of life. ${ }^{10,11}$ People with RA can play an important role in the management of their disease. A wide variety of educational programs is available as a well-established part of RA treatment. These therapeutic activities are prescribed, taught, or recommended with the aim of reducing deformities and maintaining or improving function. Symptoms including pain, fatigue, stiffness and decreased muscle strength cause significant difficulties in daily activities such as grooming and dressing, cooking, cleaning, shopping, working, and leisure activities. ${ }^{12,13}$ The physical, personal, familial, social, and vocational consequences of RA are extensive. The most important interventions in occupational therapy for RA are training of skills, counseling, education about joint protection, prescription of assistive devices, and the provision of splints. Advice or instructions on the use of assistive devices and training in self-care and productivity activities are the leading interventions for RA patients preferred by occupational therapists. ${ }^{13-18}$ However, the effect of occupational therapy on the functional performance and social participation of RA patients has not been reviewed systematically. There are several studies emphasizing that effectiveness of randomized controlled comprehensive occupational therapy interventions in patients with RA should be investigated. ${ }^{10-12}$ To our knowledge, there is no study that has investigated the client-centered occupational therapy in patients with RA. In our country, patients with rheumatic diseases consult physiotherapy clinics to reduce pain and overcome activity limitations. Occupational therapy is a new profession in Turkey; therefore, awareness about it is limited among healthcare professionals. We hope that this study draws attention to the importance of client-centered occupational therapy in rheumatic diseases in Turkey. Thus, in this study, we aimed to examine the effectiveness of client-centered occupational therapy in patients with RA.

\section{PATIENTS AND METHODS}

This randomized controlled trial included 40 patients ( 2 males, 38 females; range 39 to 60 years) with RA according to American College of Rheumatology who were enrolled between January 2010 and November 2011. The trial design was based on Consolidated Standards of Reporting Trials statement. ${ }^{13}$ Patients were divided into two groups with random sampling method as the intervention group and control group. The minimum number of patients was statistically determined as 20 for each group by a blinded statistician using power analysis. After randomization, the principal researcher informed the participants about the group allocation. Figure 1 shows recruitment process and randomization. University Committee on Ethics granted approval for the study. Written informed consents were obtained from all participants. Inclusion criteria included RA diagnosis by a rheumatologist, being aged between 18 and 65 years, not being prescribed any change in drug therapy during the six months before the trial, being at stage 2 or 3 according to American College of Rheumatology criteria, and not being in the inflammatory stage of the disease. Exclusion criteria included having cognitive impairment affecting ability to understand and complete the study questionnaire; cardiopulmonary, neurological or orthopedic procedure in the last one year; or any other health condition(s), not related to RA, which moderately to severely limit participation in activities and/or hand function. Health conditions secondary to RA (e.g., osteoarthritis, fibromyalgia, heart conditions, and carpal tunnel syndrome) were not included in the exclusion criteria.

Ten sessions of physical therapy program were implemented on the control group. Physiotherapy took approximately 45 minutes every day and consisted of pain management (hot-packs, 
cold-packs, and electrotherapy); exercises for stretching and strengthening; and educational therapy approaches (joint protection techniques, energy conservation techniques, splint and assistive devices use, etc.)

The same physical therapy was implemented to the intervention group. In addition, a clientcentered occupational therapy was performed. Occupational therapy was arranged as four or more sessions according to individual needs according to the "Guidelines for Client-Centered Occupational Therapy". 8,14 In our study, the therapist planned therapy with the patient as a decision-maker and implemented it based on the goals and priorities identified by the patients themselves to deal with various deficit occupational performance components. ${ }^{2}$ Patients were also assigned an activity schedule, which included activities to enhance the occupational performance components that were identified by the subjects as 'important' according to the COPM. The various occupational performance components addressed were personal care, functional mobility, community management, household management, work, passive recreation, active recreation, and socialization. The participants completed the COPM with the principal investigator by identifying and rating performance and satisfaction in four to five tasks which they wished to improve by the therapy sessions. Direct intervention was provided and recorded by two collaborating therapists with clinical experience ranging from two to five years. The treatment program was designed according to the patients' needs and expectations. Each session was approximately 60 to 90 minutes long, specifically designed to meet the identified goals of the patients.

All of the assessment tools used in this study were administered by assistant researchers who were trained to use the respective tools. Assessment instruments were administered before (baseline) and after treatments during one month follow-up. The data collection took approximately one hour.

Sociodemographic characteristics were recorded at baseline including age, sex, employment status, and education level categorized as low (primary school or intermediate school), intermediate (secondary school) and high (university). Disease duration and length of the treatment were also noted.

Pain was evaluated with the Turkish version of Short-Form McGill Pain Index (MPI). ${ }^{15}$ The main component of the MPI consisted of 15 descriptive adjectives for pain sensation (11 sensory and four affective), which were self-rated by patients according to intensity level on a point-rating scale $(0=$ none, $1=$ mild, $2=$ moderate, $3=$ severe $)$. The three pain scores were derived from the sum of the intensity rank values of the words chosen for sensory, affective, and total descriptors. The sensory and affective scores were calculated by adding the sensory and affective intensity values. The total score was sum of the intensity values. The MPI also included a pain intensity measure shown by the visual analog scale and the evaluative total pain intensity index of the standard MPI.

Functional status was evaluated using the Turkish version of Health Assessment Questionnaire (HAQ), which is an original measure (range 0-3) to score difficulty in performing everyday activities during the previous week. HAQ is a 20 -item selfadministered scale consisting eight subscales (dressing and grooming, arising, eating, walking, hygiene, reach, grip and "other activities"), which evaluate physical functions during the activities of daily living and yield total scores ranging from 0 (no or minimal dysfunction) to 3 (severe dysfunction). ${ }^{16}$

The Arthritis Impact Measurement Scale 2 (AIMS2) is the most commonly used measure for evaluation of disability and health status in the previous month in patients with arthritis. The measure considers five subscales (physical function, symptoms, work, psychological dimension, and social interaction), and the individual items are combined to form an aggregate score. After normalizing the score on each subscale, the range of the scores was 0-10, where higher scores indicate more problems. The Turkish version of the AIMS2 was used in this study. ${ }^{17}$

In COPM, a semi-structured interview is performed, wherein a patient identifies problems in occupational performance and prioritizes them. Treatment is based on the identified problems, and the goal is to improve performance in the areas most important to the patient. The patient scores performance in the identified problems and 
Table 1. Demographic characteristics of groups

\begin{tabular}{|c|c|c|c|c|}
\hline & \multicolumn{2}{|c|}{ Intervention group } & \multicolumn{2}{|c|}{ Control group } \\
\hline & $\%$ & Mean \pm SD & $\%$ & Mean \pm SD \\
\hline Age (years) & & $51.35 \pm 11.57$ & & $55.80 \pm 10.33$ \\
\hline Height $(\mathrm{cm})$ & & $160.20 \pm 5.27$ & & $162.20 \pm 6.05$ \\
\hline Weight $(\mathrm{kg})$ & & $70.65 \pm 10.03$ & & $72.70 \pm 11.45$ \\
\hline Disease duration (month) & & $109.80 \pm 52.72$ & & $99.20 \pm 45.98$ \\
\hline \multicolumn{5}{|l|}{ Education status } \\
\hline Primary school & 20 & & 25 & \\
\hline High school & 40 & & 35 & \\
\hline University & 40 & & 40 & \\
\hline
\end{tabular}

the satisfaction with performance. Evaluations are made twice, at the beginning and after the completion of the treatment period. For scoring the self perceived performance and satisfaction with this performance, a 10-point scale is used, where the score ranges from 1 , meaning 'not able to do it' or 'not satisfied at all', to 10, which is 'able to do it extremely well' or 'extremely satisfied'. COPM is designed to evaluate change in patients' perceptions of performance and satisfaction with performance in identified activities. The change between initial evaluation and re-evaluation is a clinically important score. The measure has its theoretical foundation in the Canadian Model of Occupational Performance focused on clientcentered praxis and occupational performance. ${ }^{18}$

Quality of life was measured using the RA Quality of Life questionnaire. ${ }^{19}$ This questionnaire consists of 30 yes/no type questions and other questions having a range from 0 to 30 , with a lower score indicating higher quality of life.

\section{Statistical analysis}

All statistical analyses were performed using the software SPSS version 10.0 (SSPS Inc., Chicago, IL, USA). Distribution and normality were determined by Shapiro-Wilk test. Comparisons between two independent samples were made by
Mann-Whitney U test. Wilcoxon signed-rank test was performed to determine whether a change occurred. The data are presented in the form of means with standard errors and percentages. A p-value of less than 0.05 was considered statistically significant.

\section{RESULTS}

The demographic characteristics of the patients are presented in Table 1 . There were no substantial clinical differences between the groups at baseline in terms of demographic factors. The majority of the patients were females. Four patients from the intervention group and two from the control group were employed. There were no losses during the follow-up and progress through the trial. The patients had problems in different joints; four patients from the intervention group and three from the control group had primarily hand joint involvement.

Baseline and follow-up pain levels were reported with MPI. While all pain scores significantly decreased in the intervention group, pain decreased significantly only in sensory score of MPI in the control group. Table 2 presents the results of pain level.

Table 2. Comparison of two groups for pain

\begin{tabular}{|c|c|c|c|c|c|c|}
\hline & \multicolumn{2}{|c|}{ Intervention group } & \multicolumn{2}{|c|}{ Control group } & \multirow[b]{3}{*}{$\mathrm{r}$} & \multirow[b]{3}{*}{$p$} \\
\hline & Pre-intervention & Post-intervention & Pre-treatment & Post-treatment & & \\
\hline & Mean \pm SD & Mean \pm SD & Mean \pm SD & Mean \pm SD & & \\
\hline McGill sensory & $7.85 \pm 2.81$ & $3.55 \pm 1.95$ & $8.85 \pm 1.98$ & $7.15 \pm 1.66$ & -4.61 & $0.00^{*}$ \\
\hline McGill affective & $0.90 \pm 0.71$ & $0.10 \pm 0.30$ & $0.90 \pm 0.44$ & $0.75 \pm 0.55$ & -3.03 & $0.002^{*}$ \\
\hline McGill visual analog scale & $4.20 \pm 1.88$ & $2.00 \pm 1.25$ & $4.10 \pm 1.77$ & $3.15 \pm 1.49$ & -3.14 & $0.002^{*}$ \\
\hline
\end{tabular}


Table 3. Comparison of two groups for Health Assessment Questionnaire scores

\begin{tabular}{|c|c|c|c|c|c|c|}
\hline & \multicolumn{2}{|c|}{ Intervention group } & \multicolumn{2}{|c|}{ Control group } & \multirow[b]{3}{*}{$\mathrm{r}$} & \multirow[b]{3}{*}{$p$} \\
\hline & Pre-intervention & Post-intervention & Pre-treatment & Post-treatment & & \\
\hline & Mean \pm SD & Mean \pm SD & Mean \pm SD & Mean \pm SD & & \\
\hline Dressing and grooming & $0.80 \pm 0.52$ & $0.30 \pm 0.47$ & $0.75 \pm 0.78$ & $0.75 \pm 0.78$ & -2.93 & $0.003^{*}$ \\
\hline Rising & $0.75 \pm 0.71$ & $0.10 \pm 0.30$ & $1.10 \pm 0.71$ & $0.95 \pm 0.68$ & -4.44 & $0.00^{*}$ \\
\hline Eating & $1.80 \pm 0.41$ & $1.00 \pm 0.32$ & $1.60 \pm 0.68$ & $1.55 \pm 0.68$ & -1.86 & 0.06 \\
\hline Walking & $0.75 \pm 0.78$ & $0.40 \pm 0.50$ & $1.55 \pm 0.60$ & $1.45 \pm 0.60$ & -2.19 & $0.02^{*}$ \\
\hline Hygiene & $0.70 \pm 0.65$ & $0.25 \pm 0.44$ & $0.80 \pm 0.69$ & $0.70 \pm 0.73$ & -4.80 & $0.00^{*}$ \\
\hline Reach & $1.45 \pm 0.75$ & $0.65 \pm 0.48$ & $1.75 \pm 0.63$ & $1.75 \pm 0.63$ & -4.80 & $0.000^{*}$ \\
\hline Grip & $2.05 \pm 0.39$ & $1.25 \pm 0.55$ & $1.65 \pm 0.58$ & $1.65 \pm 0.58$ & -5.02 & $0.00^{*}$ \\
\hline Activities & $2.05 \pm 0.39$ & $1.15 \pm 0.58$ & $2.10 \pm 0.78$ & $2.10 \pm 0.78$ & -5.53 & $0.00^{*}$ \\
\hline Total & $0.81 \pm 0.32$ & $0.36 \pm 0.19$ & $0.89 \pm 0.40$ & $0.87 \pm 0.38$ & -3.36 & $0.00^{*}$ \\
\hline
\end{tabular}

The primary outcome measure was HAQ. There was a significant decrease in all subparameters and total score of HAQ in intervention group. In the control group, no significant difference was found in subparameters of HAQ, whereas HAQ total score decreased significantly. Moreover, a comparison of groups revealed a significant difference between the groups in all HAQ scores except the eating parameter. Our results showed more significantly decreased activity limitation and participation restriction in intervention group compared to control group (Table 3).

While all AIMS2 scores decreased in the intervention group, there was only a significant difference in AIMS2 score in the control group.
All parameters of AIMS2 decreased more significantly in intervention group than control group (Table 4).

The COPM performance and satisfaction scores increased significantly after the intervention of client-centered occupational therapy; whereas, in the control group, only performance scores increased significantly. Activity performance increased more significantly in intervention group than control group. Table 5 presents the results of the COPM.

A significantly increased quality of life was also noted in the intervention group, but there was no significant increase in the control group. Table 5 shows the results of RA Quality of Life.

Table 4. Comparison of two groups for Arthritis Impact Measurement Scale 2 scores

\begin{tabular}{|c|c|c|c|c|c|c|}
\hline & \multicolumn{2}{|c|}{ Intervention group } & \multicolumn{2}{|c|}{ Control group } & \multirow[b]{3}{*}{$\mathrm{r}$} & \multirow[b]{3}{*}{$p$} \\
\hline & Pre-intervention & Post-intervention & Pre-treatment & Post-treatment & & \\
\hline & Mean \pm SD & Mean \pm SD & Mean \pm SD & Mean \pm SD & & \\
\hline Mobility & $2.87 \pm 1.62$ & $2.27 \pm 1.21$ & $3.27 \pm 1.01$ & $3.25 \pm 1.03$ & -2.95 & $0.003^{*}$ \\
\hline Walking and bending & $3.60 \pm 1.81$ & $3.20 \pm 1.48$ & $5.00 \pm 1.41$ & $4.95 \pm 1.38$ & -2.55 & $0.01^{*}$ \\
\hline Hand and finger & $4.00 \pm 1.69$ & $1.90 \pm 0.94$ & $2.12 \pm 1.49$ & $2.10 \pm 1.51$ & -5.21 & $0.00^{*}$ \\
\hline Arm function & $1.22 \pm 1.32$ & $0.82 \pm 1.10$ & $2.10 \pm 1.96$ & $2.05 \pm 1.89$ & -2.34 & $0.01^{*}$ \\
\hline Self care & $0.67 \pm 1.13$ & $0.16 \pm 0.51$ & $1.38 \pm 1.80$ & $1.25 \pm 1.61$ & -1.96 & $0.05^{*}$ \\
\hline House hold tasks & $2.76 \pm 0.93$ & $1.07 \pm 1.17$ & $2.92 \pm 1.45$ & $2.82 \pm 1.37$ & -4.76 & $0.00^{*}$ \\
\hline Social activity & $4.80 \pm 1.28$ & $4.37 \pm 0.91$ & $5.40 \pm 1.38$ & $5.37 \pm 1.36$ & -2.12 & $0.03^{*}$ \\
\hline Support from family & $3.31 \pm 2.55$ & $2.49 \pm 1.88$ & $2.68 \pm 2.67$ & $2.68 \pm 2.67$ & -3.09 & $0.002 *$ \\
\hline Arthritis pain & $5.76 \pm 1.46$ & $3.31 \pm 1.41$ & $5.82 \pm 1.42$ & $5.15 \pm 1.13$ & -4.34 & $0.00^{*}$ \\
\hline Level of tension & $6.97 \pm 9.02$ & $4.32 \pm 1.17$ & $4.95 \pm 0.87$ & $4.95 \pm 0.87$ & -3.77 & $0.00^{*}$ \\
\hline Mood & $3.76 \pm 1.16$ & $3.30 \pm 1.08$ & $4.12 \pm 1.40$ & $4.12 \pm 1.40$ & -3.33 & $0.001^{*}$ \\
\hline Satisfaction & $5.68 \pm 1.27$ & $4.09 \pm 1.21$ & $5.76 \pm 0.86$ & $5.72 \pm 0.81$ & -5.13 & $0.00^{*}$ \\
\hline Health perceptions & $6.51 \pm 1.70$ & $5.50 \pm 1.63$ & $6.68 \pm 1.08$ & $6.68 \pm 1.08$ & -2.61 & 0.009 \\
\hline Arthritis impact & $5.10 \pm 1.51$ & $4.60 \pm 1.46$ & $4.87 \pm 0.55$ & $4.87 \pm 0.55$ & -2.08 & $0.03^{*}$ \\
\hline
\end{tabular}


Table 5. Comparison of two groups for Canadian Occupational Performance Measure and Rheumatoid Arthritis Quality of Life scores

\begin{tabular}{|c|c|c|c|c|c|c|}
\hline & \multicolumn{2}{|c|}{ Intervention group } & \multicolumn{2}{|c|}{ Control group } & \multirow[b]{3}{*}{$\mathrm{r}$} & \multirow[b]{3}{*}{$p$} \\
\hline & Pre-intervention & Post-intervention & Pre-treatment & Post-treatment & & \\
\hline & Mean \pm SD & Mean \pm SD & Mean \pm SD & Mean \pm SD & & \\
\hline COPM performance & $4.71 \pm 0.93$ & $6.29 \pm 0.99$ & $4.31 \pm 1.40$ & $4.39 \pm 1.39$ & -5.56 & 0.00 \\
\hline COPM satisfaction & $2.80 \pm 1.42$ & $5.85 \pm 1.37$ & $2.48 \pm 1.55$ & $2.60 \pm 1.59$ & -5.59 & $0.00^{*}$ \\
\hline Rheumatoid Arthritis Quality of Life & $10.40 \pm 4.40$ & $7.50 \pm 3.73$ & $13.60 \pm 5.51$ & $13.60 \pm 5.51$ & -5.57 & $0.00^{*}$ \\
\hline
\end{tabular}

\section{DISCUSSION}

Although the beneficial effects of occupational therapy on function in patients with RA are pointed out in the literature, there are few studies that examine the effectiveness of comprehensive occupational therapy approaches. ${ }^{12}$ Studies have mostly focused on the effectiveness of education for joint-protection techniques. ${ }^{20-25}$ In Turkey, patients with RA are generally referred to physiotherapy for reducing pain especially in the symptomatic periods. However, occupational therapy approaches including efforts to reduce activity and participation limitations are insufficient. Our study shows short-term effects of client-centered occupational therapy in RA patients. To our knowledge, there are only two studies in the literature that have investigated effectiveness of occupational therapy in RA patients. ${ }^{12,26}$ Both studies determined that activity participations of RA patients increase more with implementation of occupational therapy (according to the HAQ measurement). When the values before and after therapy for HAQ in these studies $^{12,26}$ are compared with those reported in our study, we see a higher increase in the activity participations in the occupational therapy group. In HAQ, the subtitles of eating, cutting meat and opening a box were the most forceful manipulative skills for our patients. Although they were able to perform these activities after treatment, they stated that difficulties continued. In Turkey, accessibility to hand-assistive devices is limited. Low use of assistive devices for hand may be a reason for ongoing activity limitation in forceful manipulative hand activities.

In terms of AIMS2 score before and after treatment, while there is no difference in the control group, physical functions of patients improved in the intervention group (mobility levels, walking, arm movements, hand and finger movements, housework, etc.). Also, general pain levels reduced, participation in social activities and the overall satisfaction increased in terms of physical and social functions. Some changes in psychosocial status, such as decreased tension level and improved mental state recovery were also observed. As a result of the client-centered occupational therapy application, knowledge levels of patients about their own diseases increased and patients set targets for the solution of activity problems. Thus they were able to control their status and treatment. Patients, who started finding solutions for their own activity problems, were able to perform activities easily in due time. Their self-confidence and social participations improved while performing the related activities. For example, a patient, who was unable to go to shopping earlier, preferred a day on which he/she was not having pain, used a wheeled market bag, and went for coffee with his/her friends after shopping. In this way, he/she was able to perform both shopping activities and also social participation. In our study, the quality of life of patients with RA increased in intervention group. The reason for this might be that patients were happy when they were able to perform the activities that were important for them and which they were unable to perform earlier. This also affected the life quality in a positive way. In a recent study the COPM was used as the primary measurement method for RA patients aiming to specify the effect of comprehensive application on activity performance development. The researchers demonstrated a significant development in the study group when compared to the control group after six months. ${ }^{12}$ In our study, increased activity performance and satisfaction of patients in intervention group were more apparent than the control group. In the control group, a slight 
change was recorded in the activity performances since pain caused mobility problems, such as walking, climbing stairs up and leaning, were reduced by physiotherapy. In this study, we took the empowerment theory in a client-centered approach as a basis ${ }^{5,27}$ and showed that all patients were weak in terms of empowerment. Since our patients stated that they had no earlier knowledge about occupational therapy and drug usage except traditional rheumatology care, we provided one session of informative education for patients before referring to the client-centered approach. Thus, their awareness about their own performance problems increased during the assessment stage. When cooperation was sought with the patients during the target planning stage, they gradually got in the client-centered application stage and gained their first strength. We recognized that the decision-making and improving powers of the patients increased day by day.

A limitation of our study is that it does not show long-term effects of client-centered occupational therapy. Therefore, it might be beneficial to evaluate the effects of client-centered occupational therapy application in this patient group during a long-term follow-up period. The effectiveness of occupational therapy applications with clientcentered approach should also be assessed in other rheumatic diseases and also in other chronic diseases. Quantitative research plans may be efficient in displaying the effectiveness of clientcentered approach. In our country, occupational therapy is newly developing. This study, which is the first clinical occupational therapy intervention for rheumatologic diseases in Turkey, may lead to the development of occupational therapy in rheumatology in Turkey.

In conclusion, client-centered occupational therapy may reduce the activity limitation and participation restrictions and increase the quality of life in patients with RA. Nevertheless, further studies are necessary to investigate the long-term effects of client-centered occupational therapy in patients with RA.

\section{Declaration of conflicting interests}

The authors declared no conflicts of interest with respect to the authorship and/or publication of this article.

\section{Funding}

The authors received no financial support for the research and/or authorship of this article.

\section{REFERENCES}

1. Sumsion, T. A revised occupational therapy definition of client-centred practice. Br J Occup Ther 2000;63:304-9.

2. Sumsion $\mathrm{T}$, editor. Client-centred practice in occupational therapy. A guide to implementation. 2nd ed. Edinburgh: Churchill Livingstone; 1999.

3. Hammel KW. Client-centred philosophy: exploring privilege and power. In: Hammel KW, editor. Perspectives on Disability and Rehabilitation: Contesting assumptions, challenge, practice. Edinburgh: 1st ed. Churchill Livingstone; 2006. p. $145-64$.

4. Mortenson WB, Dyck I. Power and client-centred practice: an insider exploration of occupational therapists' experiences. Can J Occup Ther 2006;73:261-71.

5. Hammell KW. The client as the expert on their lives: Moving Forward Together: Facilitating Empowerment, Mental Health Congress, June 5, 2009. Exploring the assumptions underpinning rehabilitation. Perspectives on disability and rehabilitation: Contesting assumptions challenge. Edinburgh: Churchill Livingstone; 2009.

6. Kjeken I, Slatkowsky-Christensen B, Kvien TK, Uhlig T. Norwegian version of the Canadian Occupational Performance Measure in patients with hand osteoarthritis: validity, responsiveness, and feasibility. Arthritis Rheum 2004;51:709-15.

7. Wressle E, Lindstrand J, Neher M, Marcusson $\mathrm{J}$, Henriksson C. The Canadian Occupational Performance Measure as an outcome measure and team tool in a day treatment programme. Disabil Rehabil 2003;25:497-506.

8. Hammell KR. Client-centred practice in occupational therapy: critical reflections. Scand J Occup Ther 2013;20:174-81.

9. Malcus-Johnson P, Carlqvist C, Sturesson AL, Eberhardt K. Occupational therapy during the first 10 years of rheumatoid arthritis. Scand J Occup Ther 2005; 12:128-35.

10. Steultjens EM, Dekker J, Bouter LM, van Schaardenburg D, van Kuyk MA, van den Ende $\mathrm{CH}$. Occupational therapy for rheumatoid arthritis: a systematic review. Arthritis Rheum 2002;47:672-85.

11. Rapoliene J, Krisciunas A. The effectiveness of occupational therapy in restoring the functional state of hands in rheumatoid arthritis patients. Medicina (Kaunas) 2006;42:823-8.

12. Macedo AM, Oakley SP, Panayi GS, Kirkham BW. Functional and work outcomes improve in patients with rheumatoid arthritis who receive targeted, 
comprehensive occupational therapy. Arthritis Rheum 2009;61:1522-30.

13. Schulz KF, Altman DG, Moher D. The CONSORT statement: revised recommendations for improving the quality of reports of parallel-group randomized trials. CONSORT Group. CONSORT 2010 Statement: updated guidelines for reporting parallel group randomised trials. BMC Med 2010;8:18.

14. Canadian Association of Occupational Therapist. Occupational/ therapy guidelines for client-centred practice. Toronto: CAOT Publications ACE; 1991.

15. Yakut Y, Yakut E, Bayar K, Uygur F. Reliability and validity of the Turkish version short-form McGill pain questionnaire in patients with rheumatoid arthritis. Clin Rheumatol 2007;26:1083-7.

16. Küçükdeveci AA, Sahin H, Ataman S, Griffiths B, Tennant A. Issues in cross-cultural validity: example from the adaptation, reliability, and validity testing of a Turkish version of the Stanford Health Assessment Questionnaire. Arthritis Rheum 2004;51:14-9.

17. Atamaz F, Hepguler S, Oncu J. Translation and validation of the Turkish version of the arthritis impact measurement scales 2 in patients with knee osteoarthritis. J Rheumatol 2005;32:1331-6.

18. Eyssen IC, Beelen A, Dedding C, Cardol M, Dekker J. The reproducibility of the Canadian Occupational Performance Measure. Clin Rehabil 2005;19:888-94.

19. Kutlay S, Küçükdeveci AA, Gönül D, Tennant A. Adaptation and validation of the Turkish version of the Rheumatoid Arthritis Quality of Life Scale. Rheumatol Int 2003;23:21-6.

20. Hammond A, Freeman K. One-year outcomes of a randomized controlled trial of an educationalbehavioural joint protection programme for people with rheumatoid arthritis. Rheumatology (Oxford) 2001;40:1044-51.

21. Hammond A, Jefferson P, Jones N, Gallagher J, Jones T. Clinical applicability of an educationalbehavioural joint protection programme for people with rheumatoid arthritis. Br J Occup Ther 2002; 65:405-412.

22. Masiero S, Boniolo A, Wassermann L, Machiedo $\mathrm{H}$, Volante D, Punzi L. Effects of an educationalbehavioral joint protection program on people with moderate to severe rheumatoid arthritis: a randomized controlled trial. Clin Rheumatol 2007;26:2043-50.

23. Tuntland H, Kjeken I, Nordheim L, Falzon L, Jamtvedt $\mathrm{G}$, Hagen $\mathrm{K}$. The Cochrane review of assistive technology for rheumatoid arthritis. Eur J Phys Rehabil Med 2010;46:261-8.

24. Egan M, Brosseau L, Farmer M. Splints and orthoses for treating rheumatoid arthritis (Cochrane Review). The Cochrane Library. 4, Chichester: Wiley; 2010.

25. Hammond A, Freeman K. The long term outcomes from a randomised controlled trial of an educational behavioural joint protection programme for people with rheumatoid arthritis. Clinical Rehabilitation 2004;18:520.

26. Helewa A, Goldsmith $\mathrm{CH}$, Lee $\mathrm{P}$, Bombardier $\mathrm{C}$, Hanes B, Smythe HA, et al. Effects of occupational therapy home service on patients with rheumatoid arthritis. Lancet 1991;337:1453-6.

27. Aujoulat I, d'Hoore W, Deccache A. Patient empowerment in theory and practice: polysemy or cacophony? Patient Educ Couns 2007;66:13-20. 